\title{
Striking similarities in systemic factors contributing to decreased exercise capacity in patients with severe chronic heart failure or COPD
}

Citation for published version (APA):

Gosker, H. R., Lencer, N. H., Franssen, F. M., van der Vusse, G. J., Wouters, E. F. M., \& Schols, A. M. W. J. (2003). Striking similarities in systemic factors contributing to decreased exercise capacity in patients with severe chronic heart failure or COPD. Chest, 123(5), 1416-1424.

https://doi.org/10.1378/chest.123.5.1416

Document status and date:

Published: 01/01/2003

DOI:

10.1378/chest.123.5.1416

Document Version:

Publisher's PDF, also known as Version of record

Document license:

Taverne

Please check the document version of this publication:

- A submitted manuscript is the version of the article upon submission and before peer-review. There can be important differences between the submitted version and the official published version of record.

People interested in the research are advised to contact the author for the final version of the publication, or visit the DOI to the publisher's website.

- The final author version and the galley proof are versions of the publication after peer review.

- The final published version features the final layout of the paper including the volume, issue and page numbers.

Link to publication

\footnotetext{
General rights rights.

- You may freely distribute the URL identifying the publication in the public portal. please follow below link for the End User Agreement:

www.umlib.nl/taverne-license

Take down policy

If you believe that this document breaches copyright please contact us at:

repository@maastrichtuniversity.nl

providing details and we will investigate your claim.
}

Copyright and moral rights for the publications made accessible in the public portal are retained by the authors and/or other copyright owners and it is a condition of accessing publications that users recognise and abide by the legal requirements associated with these

- Users may download and print one copy of any publication from the public portal for the purpose of private study or research.

- You may not further distribute the material or use it for any profit-making activity or commercial gain

If the publication is distributed under the terms of Article $25 \mathrm{fa}$ of the Dutch Copyright Act, indicated by the "Taverne" license above, 


\title{
Striking Similarities in Systemic Factors Contributing to Decreased Exercise Capacity in Patients With Severe Chronic Heart Failure or COPD*
}

\author{
Harry R. Gosker, MSc; Nicole H. M. K. Lencer, MD; Frits M. E. Franssen, MD; \\ Ger J. van der Vusse, PhD; Emiel F. M. Wouters, PhD, FCCP; and \\ Annemie M. W. J. Schols, PhD
}

\begin{abstract}
Aims: Chronic heart failure (CHF) and COPD are both characterized by muscular impairment. To assess whether the severity and functional consequences of muscular impairment are disease specific, we compared skeletal muscle function, body composition, and daily activity level relative to exercise capacity between these two disorders.

Methods: Twenty-five patients with CHF and 25 patients with COPD, and 36 healthy gender- and age-matched control subjects underwent measurement of fat-free mass (FFM) [by bioelectrical impedance analysis] as an index of muscle mass. Quadriceps and biceps functions were tested by isokinetic methods, and daily activity level was assessed by the Physical Activity Scale for Elderly (PASE) questionnaire. Peak oxygen consumption ( $\left(\dot{V}_{2}\right.$ peak) was measured by incremental cycle ergometry.

Results: PASE results were similar in patients with CHF and in patients with COPD, each group scoring lower than control subjects. FFM was also lower in patients than control subjects and correlated closely with quadriceps and biceps strength in all three subgroups, $R$ values ranging from 0.63 to 0.78 , with identical slopes. FFM also correlated significantly with $\dot{V}_{2}$ peak $(p<0.05)$, but slopes were less steep in patients than in control subjects. The type and severity of muscle dysfunction were similar in each group of patients. There were no significant correlations between indexes of cardiopulmonary function and muscle function or exercise performance in patients with CHF or in patients with COPD. In both control subjects and patients, FFM was the most significant determinant of $\dot{\mathrm{V}} \mathrm{o}_{2}$ peak.

Conclusion: Muscle dysfunction is not limited to the lower limbs, but generalized and comparable between patients with CHF and patients with COPD with similar exercise capacity. FFM is a strong predictor of peripheral muscle strength, to a lesser extent of $\dot{\mathrm{V}}_{2}$ peak, and not at all of peripheral muscle endurance.

(CHEST 2003; 123:1416-1424)
\end{abstract}

Key words: chronic heart failure; COPD; daily activity level; exercise capacity; fat-free mass; isokinetic muscle function

Abbreviations: $\mathrm{BMI}=$ body mass index; $\mathrm{CHF}=$ chronic heart failure; DLCO $=$ diffusion capacity of the lung for carbon monoxide; FFM = fat-free mass; FFMI = fat-free mass index; HR = heart rate; LVEF = left ventricular ejection fraction; $\mathrm{Nm}=$ newton-meter; PASE = Physical Activity Scale for the Elderly; RQ = respiratory quotient; $\dot{\mathrm{V}} \mathrm{CO}_{2}$ peak $=$ peak carbon dioxide production; $\dot{\mathrm{VE}}=$ minute ventilation; $\dot{\mathrm{V}} \mathrm{O}_{2}$ peak $=$ peak oxygen consumption

$\mathbf{E}$ xercise intolerance is an important symptom in chronic heart failure (CHF) and COPD that exerts a large impact on the quality of life of patients with these disorders. ${ }^{1}$ Generally, research and therapy primarily focus on cardiac dysfunction in $\mathrm{CHF}$, reflected by a reduced left ventricular ejection frac-

${ }^{\star}$ From the Departments of Pulmonology (Mr. Gosker, and Drs. Franssen, Wouters, and Schols), Cardiology (Dr. Lencer), and Physiology (Dr. van der Vusse), University of Maastricht, Maastricht, the Netherlands.

Supported by a grant from the Netherlands Asthma Foundation (project number 96.16). tion (LVEF), and on lung dysfunction in COPD, reflected by a reduced $\mathrm{FEV}_{1}$; however, these indexes of primary organ failure are poor predictors of exercise capacity in moderate-to-severe disease, ${ }^{2,3}$ in particular in patients with significant exercise intolerance.

Manuscript received January 14, 2002; revision accepted November 11, 2002

Reproduction of this article is prohibited without written permission from the American College of Chest Physicians (e-mail: permissions@chestnet.org).

Correspondence to: Harry R. Gosker, MSc, Maastricht University, PO Box 616, 6200 MD Maastricht, the Netherlands; e-mail: H.Gosker@pul.unimaas.nl 
Muscle wasting and weakness, two potential determinants of reduced exercise capacity, have been demonstrated in both COPD and CHF. Anker et $\mathrm{al}^{4}$ showed reduced muscle strength in cachectic (defined as $>7 \%$ involuntary weight loss) compared to noncachectic patients with CHF. We recently demonstrated that fat-free mass $(\mathrm{FFM})$, an indirect measure of muscle mass, is a strong predictor of muscle strength in COPD. ${ }^{5}$ Since FFM is the metabolically active and oxygen-consuming tissue mass, comprised mainly of muscle tissue, it is also likely to be a determinant of exercise capacity. A positive relationship between muscle function and exercise capacity, as previously shown in both $\mathrm{COPD}^{6}$ and $\mathrm{CHF},{ }^{7}$ might therefore indirectly reflect a relationship with FFM. Muscle function is largely characterized by strength and endurance. Strength is defined as the capacity of the muscle to develop maximal force, while endurance is the capacity of the muscle to maintain a certain force to resist fatigue. Loss of either one of these components results in muscle weakness and impaired muscle performance. The relative contribution of strength and endurance to exercise capacity in COPD and CHF remains unknown. Furthermore, it is unclear whether muscle weakness is generalized or predominantly affects the lower extremities. ${ }^{6-8}$ Patients with $\mathrm{CHF}$ and patients with COPD have reduced daily activity levels, and it is therefore likely that deconditioning itself adversely affects their exercise capacity, by definition. The relative contributions of muscle function, FFM, and daily activity level to exercise capacity have not been studied in CHF or in COPD. Furthermore, no study has yet made a direct comparison between the two patient groups.

Therefore, the first objective of the present study was to establish if muscle function, FFM, and daily activity level are similarly reduced in patients with CHF and patients with COPD and to what extent these factors are determinants of exercise capacity. The second objective of this study was to examine whether impaired peripheral muscle strength and endurance affects upper and lower limbs in patients with CHF and patients with COPD. For these purposes, we carefully assessed cardiac and pulmonary function, body composition, peripheral muscle function, and daily activity level in patients with COPD, patients with $\mathrm{CHF}$, and healthy agematched control subjects.

\section{Materials AND Methods}

\section{Study Population}

Groups of 25 patients with COPD with moderate-to-severe airflow obstruction, 25 patients with moderate-to-severe $\mathrm{CHF}$, and 36 healthy age-matched volunteers were studied. All pulmonary patients had COPD according to American Thoracic Society guidelines ${ }^{9}$ and chronic airflow limitation, defined as measured $\mathrm{FEV}_{1}<70 \%$ of reference $\mathrm{FEV}_{1}$. Furthermore, patients with COPD had irreversible obstructive airway disease $(<10 \%$ improvement of $\mathrm{FEV}_{1}$ predicted baseline after $\beta_{2}$-agonist inhalation). Patients with COPD were in clinically stable condition and not having respiratory tract infection or exacerbation of their disease at least 4 weeks prior to the study. Other exclusion criteria for the COPD group were concomitant confounding diseases like malignancies, GI disorders, severe endocrine disorders, CHF, or recent surgery. The cardiac patients had CHF based on clinical symptoms according to the Framingham criteria, ${ }^{10}$ LVEF $<45 \%$, and were in clinically stable condition. All patients with CHF were controlled at the outpatient clinic of the university Hospital of Maastricht. The origins of heart failure were idiopathic $(n=7)$, ischemic $(n=8)$, valvular disease $(n=1)$, multiple origins $(n=6)$, and miscellaneous $(n=3)$. They were all receiving extensive medication regiments: angiotensin-converting enzyme inhibitors $(\mathrm{N}=24)$, diuretics $(\mathrm{n}=24), \quad \beta$-blockers $(\mathrm{n}=16)$, and nitrates $(\mathrm{n}=16)$. Warfarin was used by 20 patients. Exclusion criteria for the CHF group were noncardiac disease with life expectancy $<1$ year, episodes of heart failure within the previous 2 months, unstable angina pectoris, scheduled for percutaneous transluminal coronary angioplasty or coronary artery bypass grafting, operable valvular disease, kidney failure (creatinine level $>250 \mu \mathrm{mol} / \mathrm{L}$ ), restrictive cardiomyopathy, hypertrophic cardiomyopathy, primary pulmonary hypertension, diabetes mellitus, COPD, psychiatric disorder, or correctable cause of heart failure. The healthy age-matched control subjects were volunteers recruited through advertisement in a local newspaper. They underwent a physical examination by a physician to ensure that they were free from significant pulmonary or cardiac disease. Written informed consent was obtained from all subjects, and the study was approved by the medical ethical committee of the University Hospital Maastricht (Maastricht, the Netherlands).

\section{Assessment of Body Composition}

FFM was measured by bioelectrical impedance (Xitron 4000b; Xitron Technologies; San Diego, CA). Resistance was measured in supine position at the right side as described by Lukaski et al. ${ }^{11}$ A patient-specific regression equation was used to calculate FFM in patients with COPD. ${ }^{12}$ This equation was also used to calculate the FFM of patients with CHF (validated against the deuterium dilution method). Body mass index (BMI) was calculated by dividing whole body weight by the squared body height in order to correct for differences in body size. ${ }^{13}$ For the same reason the FFM index (FFMI) was calculated by dividing the FFM by the squared body height. ${ }^{13}$

\section{Cardiopulmonary Function}

All patients and control subjects underwent spirometry to determine the $\mathrm{FEV}_{1}$, with the highest value from at least three technically acceptable assessments being used. Diffusion capacity of the lung for carbon monoxide (DLCO) was measured using the single-breath method (Masterlab; Jaeger; Wurzburg, Germany). All values obtained were related to a reference value and expressed as percentage of the predicted value. ${ }^{14}$ In patients with COPD as well as in patients with CHF, $\mathrm{FEV}_{1}$ and DLCO were significantly lower than in control subjects; but as expected, the $\mathrm{FEV}_{1}$ and the DLCO were markedly lower in patients with COPD than in patients with $\mathrm{CHF}$ (Table 1). In all patients with $\mathrm{CHF}$, LVEF was measured by M-mode echocardiogram to assess 
Table 1-Subject Characteristics*

\begin{tabular}{|c|c|c|c|}
\hline Characteristics & Control Subjects & COPD & $\mathrm{CHF}$ \\
\hline Subjects (male/female), No. & $36(24 / 12)$ & $25(16 / 9)$ & $25(17 / 8)$ \\
\hline Age, yr & $61 \pm 5.9$ & $62 \pm 9.8$ & $63 \pm 8.0$ \\
\hline Length, cm & $172 \pm 9$ & $168 \pm 7$ & $168 \pm 9$ \\
\hline Weight, kg & $78.4 \pm 11.6$ & $67.8 \pm 15.1 \uparrow$ & $71.9 \pm 11.9$ \\
\hline BMI & $26.4 \pm 2.5$ & $23.9 \pm 4.1 \dagger$ & $25.3 \pm 3.7$ \\
\hline FFM, kg & $58.7 \pm 10.8$ & $49.5 \pm 8.2 \ddagger$ & $50.1 \pm 9.2^{+}$ \\
\hline FFMI, $\mathrm{kg} / \mathrm{m}^{2}$ & $19.7 \pm 2.1$ & $17.5 \pm 2.0 \pm$ & $17.6 \pm 2.1^{t}$ \\
\hline $\mathrm{FEV}_{1}, \%$ predicted & $111 \pm 17$ & $32 \pm 11+$ & $90 \pm 22+\frac{+}{+} \$$ \\
\hline DLCO, $\%$ predicted & $112 \pm 17$ & 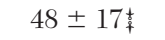 & 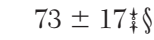 \\
\hline DLCO/alveolar volume, $\%$ predicted & $110 \pm 17$ & $57 \pm 20_{+}^{t}$ & 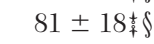 \\
\hline LVEF, \% & & & $29 \pm 7.2$ \\
\hline PASE score & $140 \pm 64$ & 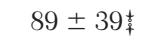 & $83 \pm 56+\frac{+}{+}$ \\
\hline
\end{tabular}

*Data are presented as mean \pm SD unless otherwise indicated.

tp $<0.01$ vs control subjects.

$+\begin{aligned} & \mathrm{p} \\ & +\mathrm{p}\end{aligned}$

$\S \mathrm{p} \leq 0.001, \mathrm{COPD}$ vs $\mathrm{CHF}$.

cardiac function. In patients with COPD and control subjects, 12-lead ECGs were evaluated, since echocardiography was not available for logistical reasons. Five patients with COPD showed abnormalities on the ECG: one with prolonged PR interval, one with incomplete left bundle branch block, and one with repolarization disturbances inferolaterally. The two others showed left ventricular hypertrophy, together with conduction disturbances or left bundle branch block and abnormal ST segments. Six patients with COPD had normal ECG findings. The other 14 patients with COPD had signs of right ventricular conduction delay, as there were axis shifts to vertical or right, s in lead I, q in lead III, (incomplete)-right bundle branch block. Only one patient had QRS widening of $120 \mathrm{~ms}$. All patients with COPD had sinus rhythm. In the control group, ECGs were available from 20 patients: 11 subjects had normal ECG findings, 9 subjects showed right ventricular conduction delay as defined above, 1 of them together with probable anterior wall myocardial infarction and 2 of them with inferior wall abnormalities. All subjects in the control group had sinus rhythm.

\section{Muscle Function}

Isokinetic muscle functions (which are described and defined elsewhere ${ }^{15}$ ) of the dominant knee extensor (quadriceps) and elbow flexor muscles (biceps) were measured using a Biodex dynamometer (Biodex Corporation; Shirley, NY) or a Cybex II+ dynamometer (Cybex; Ronkonkoma, NY). There were no differences between results obtained using either machine (unpublished results). To assess leg muscle function, subjects were seated upright on the chair of the dynamometer and provided with back support. At the level of the chest, pelvis, and thigh, subjects were restrained with straps. The hip joint was at an angle between $90^{\circ}$ and $100^{\circ}$ of flexion during testing. The lever arm was attached to the distal part of the tibia, and its axis of rotation was visually aligned with the anatomic axis of flexion of the knee joint. Subjects were instructed to keep their hands on their thighs during testing. To assess arm muscle function, subjects sat in upright on a chair with the shoulder of the dominant arm placed in $90^{\circ}$ abduction. The upper arm was supported and fixed with a belt in the horizontal plane on an adjustable stand. The ventral side of the forearm was placed in the frontal plane, and the handgrip of the lever arm was held by the subjects. The lateral epicondyle of the humerus was used as the axis of elbow rotation and was visually aligned with the axis of rotation of the dyna- mometer. Subjects were instructed to keep their contralateral hand on their thigh. The isokinetic testing protocols of the dominant upper and lower extremities consisted of 15 sequential voluntary maximal contractions at an angular velocity of $90 \%$ s. Maximal isokinetic strength was defined as the highest peak torque (in newton-meters $[\mathrm{Nm}]$ ) in this series of 15 .

Fatigue was defined as the proportional decline in peak torque during 14 successive isokinetic flexions; the peak torques of the successive contractions were expressed as a percentage of the highest peak torque. The first contraction was excluded from analysis because this value is unreliable due to the fact that the starting maneuver is often submaximal. A linear curve was fitted through the calculated points. The slope of this curve was used to calculate the relative change in peak torque as a measure of muscle fatigue. Series in which the slope was ascending or in which the curve had an $R^{2}<0.209$ were excluded. The $R^{2}$ value is based on the critical value of the Pearson correlation coefficient at a one-tailed $\mathrm{p}$ value of 0.10 and 13 degrees of freedom. For comparison of upper- and lower-limb muscle functions, relative muscle strength and fatigue values were expressed as the percentage of mean control values and were calculated separately for male and female subjects.

\section{Exercise Capacity}

All subjects performed an incremental exercise test on an electrically braked cycle ergometer (Corival 400; Lode; Groningen, the Netherlands; or Ergo-metrics 900; Ergoline; Frankfurt, Germany) under supervision of a chest physician or a cardiologist. Before the start of the test, while seated on the cycle ergometer, ventilation characteristics at rest were analyzed over a period of $2 \mathrm{~min}$. During the entire exercise test, expired gases were analyzed using breath-by-breath analysis through a breathing mask (Oxycon; Jaeger). Heart rate (HR), systolic/diastolic BP, and percutaneous oxygen saturation were monitored. After $1 \mathrm{~min}$ of unloaded cycling, power was increased by $10 \mathrm{~W} / \mathrm{min}$ for patients. For the control subjects, the load was increased with 15 to $25 \mathrm{~W} / \mathrm{min}$, so that the length of the exercise test was comparable for patients and control subjects. None of the subjects knew the exercise load, and all were encouraged to cycle at 60 revolutions per minute until exhaustion. Peak oxygen consumption $\left(\mathrm{V}_{2}\right.$ peak) was measured at the moment of cessation of the exercise. Peak HR reserve was calculated as $100 \%-(100 \times$ peak HR $) /(220-$ age $),{ }^{16}$ and peak ventilatory 
(minute ventilation $[\dot{\mathrm{V} E}]$ ) reserve was calculated as $100 \%-(100 \times$ peak $\dot{\mathrm{VE}}) ;\left(\mathrm{FEV}_{1} \times 37.5\right) .{ }^{16,17}$

\section{Questionnaire}

The daily activity level was assessed through the Physical Activity Scale for the Elderly (PASE) questionnaire (Dutch version). ${ }^{18}$ Questions deal with physical activities during the most recent 7 days, such as leisure, sports, housework, and gardening.

\section{Statistical Analysis}

Data were analyzed with the unpaired Student $t$ test (corrected for unequal variances, if appropriate), one-way analysis of variance (with unpaired Student $t$ test as post hoc test), or the Pearson correlation test, as appropriate. ${ }^{19}$ For the comparison of relative strength and upper- and lower-limb muscle function, the Student $t$ test for paired data was used. Slopes and intercepts of regression lines were statistically compared using a small-sample $t$ test, as described by Kleinbaum et al. ${ }^{20} \mathrm{~A}$ two-tailed probability value of $<0.05$ was considered statistically significant. Data are shown as mean $\pm \mathrm{SD}$.

\section{RESULTS}

\section{Subject Characteristics}

Twenty-five patients with COPD (16 men and 9 women), 25 patients with CHF (17 men and 8 women), and 36 healthy control subjects ( 24 men and 12 women) participated in this study (Table 1). There were no differences in gender or age between the groups. Only patients with COPD had a lower BMI than control subjects; however, FFMI was reduced in patients with COPD as well as in patients with CHF compared to healthy subjects. PASE score was significantly lower in both patient groups than in control subjects, but there was no difference between patients with COPD and patients with CHF.

\section{Incremental Exercise Test}

Peak exercise data are shown in Table 2. In patients, exercise capacity, assessed by bicycle er- gometry $\left(\dot{\mathrm{V}}_{2}\right.$ peak), was about $50 \%$ of that in control subjects. The difference between the CHF and COPD patient groups was small and statistically insignificant. There was also no difference in $\mathrm{V}_{2}$ peak between patients with COPD with and without abnormalities on the ECG (not shown). Ventilation reserve and respiratory quotient (RQ) were significantly lower in patients with $\mathrm{CHF}$ and patients with COPD compared to control subjects, but only in patients with COPD was the maximum ventilation reached and was the peak $R Q<1$. Only the control subjects reached their predicted maximal peak HRs.

\section{Muscle Function}

Quadriceps strength (Fig 1, top, A) was lower in patients with COPD (85 Nm, p $\leq 0.001)$ and patients with CHF $(84 \mathrm{Nm}, \mathrm{p} \leq 0.001)$ than in control subjects (118 Nm). Biceps strength (Fig 1, top, A) was also lower in patients with COPD $(27 \mathrm{Nm}$, $\mathrm{p} \leq 0.001)$ and patients with CHF $(26 \mathrm{Nm}, \mathrm{p} \leq 0.001)$ compared to control subjects (38 Nm). Compared to control subjects, there was no significant difference between relative quadriceps and biceps strength in patients with COPD (78\% vs $77 \%$ ) or in patients with CHF (72\% vs 74\%). Quadriceps fatigue (Fig 1, bottom, $B)$, measured as the proportional decline in peak torque during 14 successive isokinetic extensions, was higher in patients with COPD $(28 \%, \mathrm{p}=0.001)$ and patients with $\mathrm{CHF}(30 \%, \mathrm{p}=0.002)$, compared to healthy subjects (21\%). Biceps fatigue (Fig 1, bottom, $B$ ), measured as the proportional decline in peak torque during 14 successive isokinetic flexions, was also markedly higher in patients with COPD and patients with CHF than in control subjects (42\% vs $32 \%$, $\mathrm{p}<0.007$ ). There were no statistically significant differences between patients with COPD and patients with CHF. Relative fatigue (as the percentage of mean control values) was also not significantly different between quadriceps and biceps in patients with COPD

Table 2-Peak Exercise Test Data*

\begin{tabular}{|c|c|c|c|}
\hline Variables & Control Subjects & COPD & $\mathrm{CHF}$ \\
\hline$\dot{\mathrm{V}} \mathrm{O}_{2}$ peak, $\mathrm{mL} / \mathrm{min}$ & $2,129 \pm 659$ & $840 \pm 261 \uparrow$ & $1,092 \pm 271 \uparrow$ \\
\hline $\mathrm{VO}_{2}$ peak/weight, $\mathrm{mL} / \mathrm{kg} / \mathrm{min}$ & $27.1 \pm 6.5$ & $12.8 \pm 3.8 \uparrow$ & $15.3 \pm 3.3 \uparrow$ \\
\hline$\dot{\mathrm{V}} \mathrm{CO}_{2}$ peak, $\mathrm{mL} / \mathrm{min}$ & $2,636 \pm 788$ & $840 \pm 269 \uparrow$ & $1,234 \pm 3289_{+}^{t}$ \\
\hline$\dot{\mathrm{V}} \mathrm{CO}_{2}$ peak/weight, $\mathrm{mL} / \mathrm{kg} / \mathrm{min}$ & $33.8 \pm 8$ & $13.0 \pm 4 \uparrow$ & $17.3 \pm 44_{+}^{+}$ \\
\hline $\mathrm{RQ}$ peak & $1.21 \pm 0.08$ & $0.96 \pm 0.10 \dagger$ & $1.11 \pm 0.08+\$$ \\
\hline$\dot{V}$ E peak, \% predicted & $88 \pm 26$ & $36 \pm 13 \uparrow$ & $48 \pm 13 十^{+}+{ }^{\circ}$ \\
\hline$\dot{V} \mathbf{E}$ reserve, \% & $26 \pm 16$ & $-9 \pm 29 \uparrow$ & $46 \pm 20+\S$ \\
\hline HR peak, beats/min & $156 \pm 13$ & $121 \pm 17 \uparrow$ & $113 \pm 24 \uparrow$ \\
\hline $\mathrm{HR}$ reserve, \% & $0 \pm 7$ & $24 \pm 11 \uparrow$ & $18 \pm 14 \uparrow$ \\
\hline
\end{tabular}

\footnotetext{
*Data are presented as mean $\pm \mathrm{SD} . \dot{\mathrm{V}} \mathrm{CO}_{2}$ peak $=$ peak carbon monoxide production.

$\dagger_{\mathrm{p}} \leq 0.001$ vs control subjects.

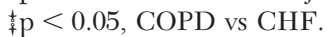

$\$ \mathrm{p} \leq 0.001$, COPD vs CHF.
} 


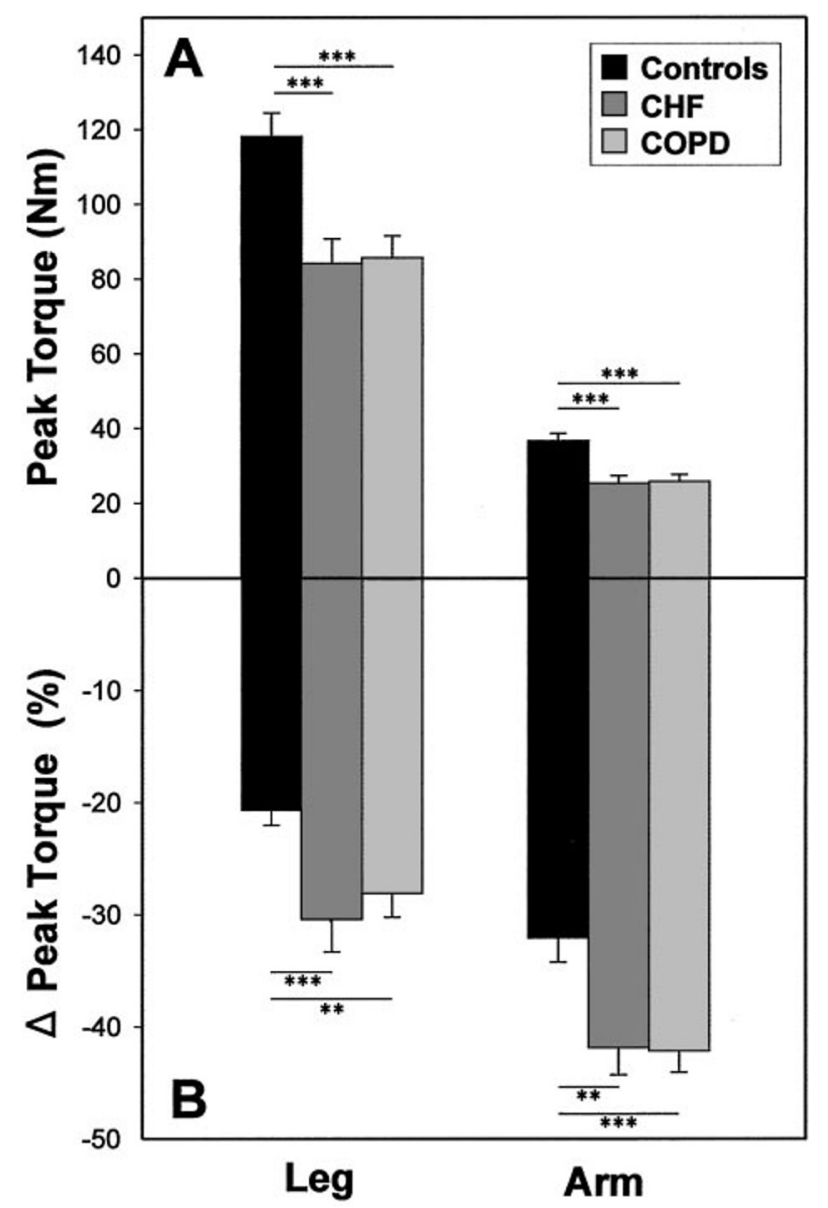

FIGURE 1. Muscle strength (expressed as the maximal torque) and fatigue (expressed as the proportional decline in peak torque). Top, A: Leg and arm muscle strength. Bottom, B: Leg and arm muscle fatigue. ${ }^{* *} \mathrm{p} \leq 0.01 ;{ }^{* * *} \mathrm{p} \leq 0.001$; error bars represent SEM

(133 $\pm 32 \%$ vs $134 \pm 34 \%$ ) or in patients with $\mathrm{CHF}$ $(159 \pm 44 \%$ vs $130 \pm 42 \%)$.

\section{Correlations}

In each group (COPD, CHF, and control), quadriceps and biceps maximal torques correlated strongly with the FFM, as shown in Figure 2, top left, $A$, and bottom left, $B$, respectively. There were no differences between the slopes of the individual subgroup regression lines in upper or lower limbs. Within each group, quadriceps and biceps strength correlated significantly with each other (data not shown). There was no relationship between quadriceps or biceps fatigue and FFM (Fig 2, top right, $C$, and bottom right, $D$, respectively). In addition, there was no relation between the PASE score and peripheral muscle maximal torque or fatigue (data not shown).

A strong correlation between the $\mathrm{V}_{2}$ peak and the
FFM $(r=0.843, \mathrm{p} \leq 0.001)$ was found in healthy control subjects, as shown in Figure 3. A weaker, but significant, relation was present in patients with COPD $(r=0.563, \quad \mathrm{p}=0.005)$ and patients with $\mathrm{CHF}$ $(r=0.484, \mathrm{p}=0.017)$. Positive correlations were also found between the $\mathrm{VO}_{2}$ peak and quadriceps strength in control subjects $(r=0.758, \mathrm{p} \leq 0.001)$, patients with COPD $(r=0.498, \mathrm{p}=0.018)$, and patients with $\mathrm{CHF}$ $(r=0.749, \mathrm{p} \leq 0.001)$. Quadriceps fatigue $\mathrm{did}$ not correlate with the $\dot{\mathrm{V}}_{2}$ peak in any of the three study groups. In patients with COPD, the $\mathrm{FEV}_{1}$ (Fig 4, left, A) or DLCo (not shown) did not correlate with the $\dot{\mathrm{V}} \mathrm{O}_{2}$ peak, nor with peak exercise capacity as measured in watts (data not shown). Similarly, in patients with CHF, the LVEF (Fig 4, right, B), FEV 1 , or DLCO (not shown) did not correlate with the $\dot{\mathrm{V}}_{2}$ peak. In control subjects, the PASE score correlated with the $\mathrm{VO}_{2}$ peak $(r=0.400, \mathrm{p}=0.032)$. In patients with COPD, this relation was absent. In patients with CHF, there was a correlation between the $\dot{\mathrm{V}}_{2}$ peak and the PASE score $(r=0.645, \mathrm{p}=0.001)$, although this statistical significance is based on one outlier (correlation without the outlier, $r=0.428, \mathrm{p}=0.053$ ). There were no correlations between the PASE score and LVEF or $\mathrm{FEV}_{1}$ in patients.

\section{Discussion}

In the current study we demonstrate that both COPD and CHF, two distinct disorders with a comparably decreased exercise capacity, show striking similarities with respect to muscle dysfunction, loss of FFM, and reduced daily activity level when compared to age-matched healthy control subjects. We also show that peripheral skeletal muscle weakness is generalized in both disorders with upper and lower limb muscle function being equally affected. Furthermore, as in control subjects, the FFM is an especially strong predictor of exercise capacity, in contrast to common indexes of primary organ failure $\left(\mathrm{FEV}_{1}\right.$ in COPD and LVEF in CHF).

FFM was equally reduced in patients with COPD and patients with CHF compared to control subjects, despite a lower BMI in the patients with COPD. This implies that in patients with CHF, protein balance may be affected in a manner disproportionate to energy balance, even in weight-stable patients. Assessment of the FFM instead of body weight therefore appears important in nutritional assessment, especially in $\mathrm{CHF}$ where, in contrast to COPD, this is not a common procedure. Our results are in agreement with previous studies showing that these indexes of the primary organ failure (LVEF and $\mathrm{FEV}_{1}$ ) are poor predictors of exercise capacity in moderate-to-severely diseased patients.,2,21,22 In- 

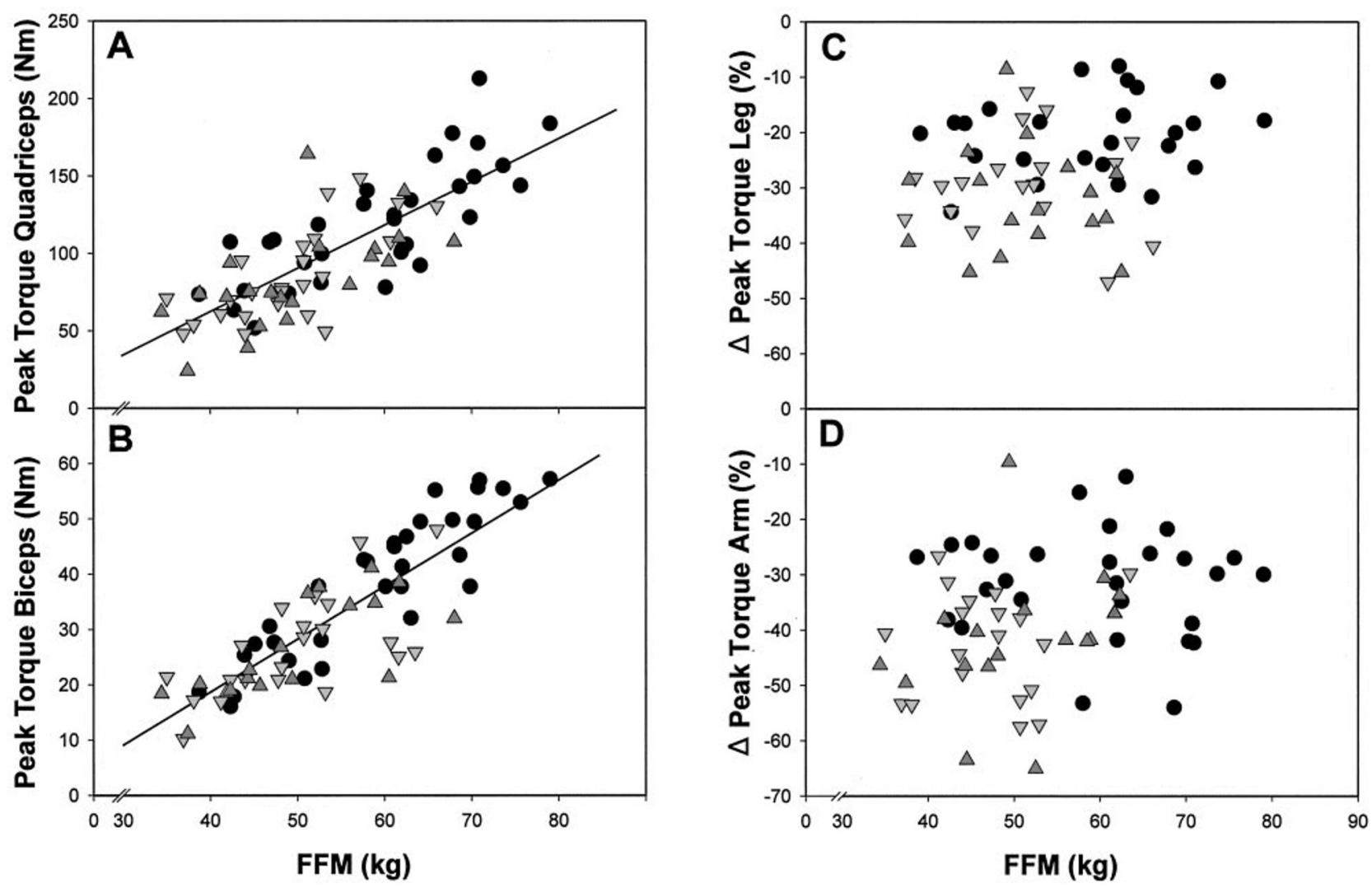

FiguRE 2. Relation between peripheral muscle function and FFM. Top left, A: Leg muscle strength. Slopes of the regression lines were not different between groups (control subjects, $r=0.78, \mathrm{p} \leq 0.001$; patients with COPD, $r=0.73, \mathrm{p} \leq 0.001$; patients with CHF, $r=0.63, \mathrm{p}=0.002)$. Bottom left, $B$ : Arm muscle strength. Slopes of the regression lines were not different between groups (control subjects, $r=0.90, \mathrm{p} \leq 0.001$; patients with COPD, $r=0.66, \mathrm{p}=0.001$; patients with $\mathrm{CHF}, r=0.75$, $\mathrm{p} \leq 0.001$. Top right, $C$ : Leg muscle fatigue; no relation with FFM. Bottom right, $D$ : Arm muscle fatigue; no relation with FFM. $=$ control subjects; $\nabla=$ patients with COPD; $\Delta=$ patients with $\mathrm{CHF}$; diagonal lines indicate relation in all subjects.

stead, we found that both in healthy subjects and in the two patient groups, the quadriceps strength and the FFM correlated with the $\dot{V}_{2}$ peak. In all groups, both control subjects and patients, the same strong relation between FFM and quadriceps or biceps strength was found, whereas the FFM did not correlate with muscle fatigue. It is obvious that peripheral muscle strength depends largely on the FFM, thereby explaining why quadriceps strength correlates with the $\dot{\mathrm{V}}_{2}$ peak. We thus demonstrate that the FFM is an important determinant of exercise capacity; however, this relation was weaker in the patient groups than in control subjects, suggesting that other factors are involved in the impaired exercise capacity and increased muscle fatigue in patients with COPD and patients with CHF.

Besides muscle wasting, intrinsic muscular abnormalities might be involved in skeletal muscle dysfunction and exercise intolerance. We recently reviewed intrinsic muscular abnormalities, such as altered fiber-type distribution and metabolic profile, in COPD and CHF. ${ }^{23}$ Although no studies have yet performed a direct comparison, striking similarities were also found here, pointing toward a decreased oxidative capacity. Physical inactivity is frequently assumed to have a negative or "detraining" effect on exercise capacity, although this influence has never been studied in CHF and COPD. In the present study, daily physical activity level expressed as the PASE score was approximately $39 \%$ lower in patients than in control subjects, but not different between patients with COPD and patients with CHF. The PASE score is an expression of exercise capacity in healthy control subjects, but it remains unclear from our data whether it is also true for patients. Since the observed relationship in patients with CHF between PASE score and $\mathrm{V}_{2}$ peak in this study is based on one outlier, the possible connection between daily activity level and the $\mathrm{V}_{2}$ peak needs further investigation. Nevertheless, whether PASE score is or is not a predictor of exercise capacity in patients, it appears less important than FFM in these severely disabled 


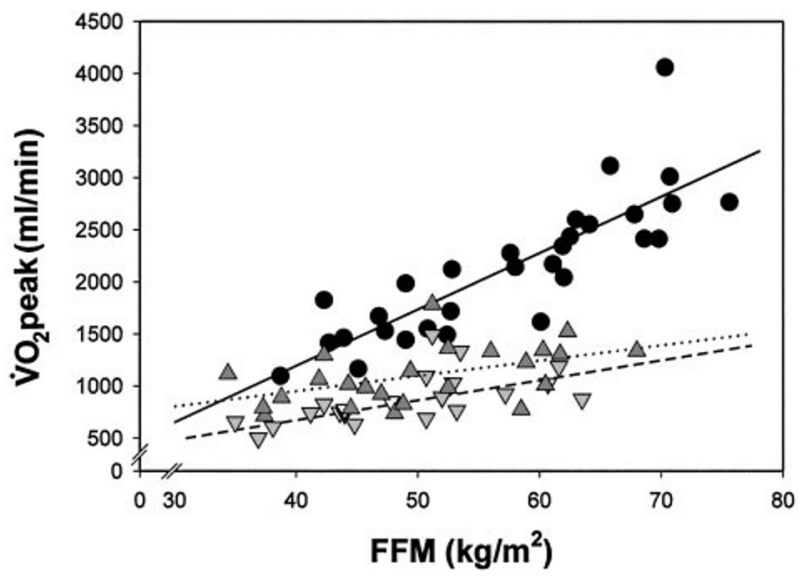

FIGURE 3. Relation between exercise capacity and FFM. $\boldsymbol{0}=$ control subjects (solid diagonal line, $r=0.84, \mathrm{p} \leq 0.001$ ); $\nabla=$ patients with COPD (dashed line, $r=0.56, \mathrm{p}=0.005$ ); $\Delta=$ patients with CHF (dotted line, $r=0.48, \mathrm{p}=0.017$ ). Slopes of patient regression lines were significantly less steep than that of the control group, with no difference between patients with COPD and patients with CHF.

patients. We therefore conclude that a reduced daily activity level may negatively affect exercise capacity in patients with COPD and patients with CHF, but its role should not be overinterpreted.

Although muscle weakness in patients with COPD and patients with $\mathrm{CHF}$ has been reported before, $, 1,8,21$ it remains unclear from the literature whether muscle weakness is generalized and of similar severity in these disorders. Only few studies compared strength of different muscle groups, and some of them suggested that upper-limb muscle strength is relatively preserved. ${ }^{6-8}$ It is difficult to compare these studies because of differences in methods and target muscles measured. For the lower limb, the quadriceps muscle is commonly tested, but for the upper limb, a wide diversity of muscle groups have been tested, such as the flexor digitorum (handgrip force), adductor pollicis, biceps, deltoid, or shoulder abductors. To avoid this problem in the present study, quadriceps and biceps strength and fatigue were therefore measured with the same isokinetic protocol. Neither patients with COPD nor patients with CHF demonstrated preserved upper-limb muscle strength relative to lowerlimb muscle strength. We therefore conclude that skeletal muscle weakness is generalized in both disorders.

In this study, pulmonary function was impaired in patients with $\mathrm{CHF}$, though obviously not to the same degree as in patients with COPD. This is shown by the somewhat lower $\mathrm{FEV}_{1}$, but in particular by the reduced DLCO. Even if corrected for the alveolar volume, the DLCo was still decreased, which was also observed by Puri et al, ${ }^{24}$ whose data suggested intrinsic abnormalities of the alveolar-capillary membrane. In turn, cardiac function may to some degree be impaired in patients with COPD. Recently, left ventricular dysfunction was found in $32 \%$ of patients with COPD in deteriorating condition, ${ }^{25}$ and in about $20 \%$ of patients in clinically stable condition. ${ }^{26}$ Since it is known that left ventricular dysfunction is very unlikely in subjects with a normal ECG finding, ${ }^{27}$ we evaluated the ECGs of patients with COPD and healthy control subjects. A substantial part of the patients with COPD had some degree of right ventricular conduction delay, which is a common phenomenon in progressive $\mathrm{COPD}^{28}$ and can also be a normal electrophysiological variant. ${ }^{29,30}$ Since the literature is controversial with respect to the interdependency of left and right ventricular dysfunction, ${ }^{28,31}$ some degree of left ventricular dysfunction cannot be excluded in this study. Five patients with COPD had abnormal ECG findings, but none of them had signs of heart failure on physical examination nor used cardiac medication. The 20 control subjects showed no ECG abnormalities except right

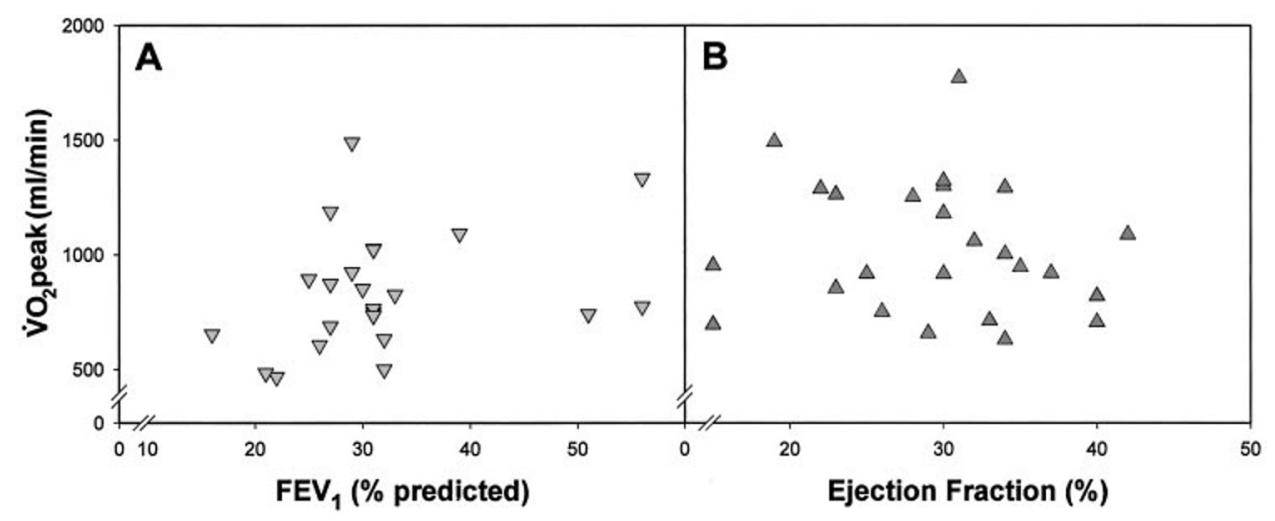

FIGURE 4. Relation between exercise capacity and primary organ function in patients with COPD $(\nabla)$ $[$ left, A] and patients with $\mathrm{CHF}(\triangle)[$ right, B]. There were no correlations. 
ventricular conduction delay, which is often seen in the normal population. The three subjects with anterior and inferior wall abnormalities also had no signs of left ventricular dysfunction on physical examination. Furthermore, the peak ventilatory and HR reserve values clearly demonstrated that patients with COPD were primarily limited by their reduced ventilatory capacity and not by cardiac function, showing that a potential cardiac impairment is subordinate to the pulmonary impairment in this group. Our data also show that patients with $\mathrm{CHF}$ were not ventilatory limited during the exhausting cycling exercise (their maximum peak HRs were not reached either, but this is due to the fact that most patients received $\beta$-blockers). These results do, however, emphasize the need to adjust for both cardiac and pulmonary organ dysfunction in these patient groups when evaluating the impact of systemic impairment.

In summary, we conclude that skeletal muscle wasting and weakness are generalized in patients with COPD and patients with CHF with similar exercise intolerance. The FFM and daily activity level are strong predictors of exercise capacity in healthy control subjects. The FFM is also a significant determinant of exercise capacity in patients with COPD and patients with CHF, in addition to other yet unidentified systemic factors. This study strengthens the importance of rehabilitation in both disorders, and mutual exchange of studies and experience in treatment modalities including nutrition, exercise, and anabolic medication.

ACKNOWLEDGMENT: We thank Petra Heuts, Femke Ellens, and Dr. Matthijs Hesselink for assistance with isokinetic muscle testing.

\section{REFERENCES}

1 Hamilton AL, Killian KJ, Summers E, et al. Muscle strength, symptom intensity, and exercise capacity in patients with cardiorespiratory disorders. Am J Respir Crit Care Med 1995; 152:2021-2031

2 Steele IC, Moore A, Nugent AM, et al. Non-invasive measurement of cardiac output and ventricular ejection fractions in chronic cardiac failure: relationship to impaired exercise tolerance. Clin Sci 1997; 93:195-203

3 Cotes JE, Zejda J, King B. Lung function impairment as a guide to exercise limitation in work-related lung disorders. Am Rev Respir Dis 1988; 137:1089-1093

4 Anker SD, Swan JW, Volterrani M, et al. The influence of muscle mass, strength, fatigability and blood flow on exercise capacity in cachectic and non-cachectic patients with chronic heart failure. Eur Heart J 1997; 18:259-269

5 Engelen MP, Schols AM, Does JD, et al. Skeletal muscle weakness is associated with wasting of extremity fat-free mass but not with airflow obstruction in patients with chronic obstructive pulmonary disease. Am J Clin Nutr 2000; 71:733738

6 Gosselink R, Troosters T, Decramer M. Peripheral muscle weakness contributes to exercise limitation in COPD. Am J
Respir Crit Care Med 1996; 153:976-980

7 Buller NP, Jones D, Poole-Wilson PA. Direct measurement of skeletal muscle fatigue in patients with chronic heart failure. Br Heart J 1991; 65:20-24

8 Bernard S, LeBlanc P, Whittom F, et al. Peripheral muscle weakness in patients with chronic obstructive pulmonary disease. Am J Respir Crit Care Med 1998; 158:629-634

9 American Thoracic Society. Standards for the diagnosis and care of patients with chronic obstructive pulmonary disease (COPD) and asthma. Am Rev Respir Dis 1987; 136:225-244

10 McKee PA, Castelli WP, McNamara PM, et al. The natural history of congestive heart failure: the Framingham study. N Engl J Med 1971; 285:1441-1446

11 Lukaski HC, Johnson PE, Bolonchuk WW, et al. Assessment of fat-free mass using bioelectrical impedance measurements of the human body. Am J Clin Nutr 1985; 41:810-817

12 Schols AM, Wouters EF, Soeters PB, et al. Body composition by bioelectrical-impedance analysis compared with deuterium dilution and skinfold anthropometry in patients with chronic obstructive pulmonary disease. Am J Clin Nutr 1991; $53: 421-424$

13 VanItallie TB, Yang MU, Heymsfield SB, et al. Heightnormalized indices of the body's fat-free mass and fat mass: potentially useful indicators of nutritional status. Am J Clin Nutr 1990; 52:953-959

14 Quanjer P, Tammeling GJ, Cotes JE, et al. Standardized lung function testing. Eur Respir J 1993; 6:5-40

15 Dvir Z. Isokinetics: muscle testing, interpretation and clinical applications. 1st ed. Edinburgh, UK: Churchill Livingstone, $1995 ; 199$

16 Wasserman K, Hansen JE, Sue DY, et al. Principles of exercise testing and interpretation. 2nd ed. Philadelphia, PA: Lea \& Febiger, 1994; 479

17 Carter R, Peavler M, Zinkgraf S, et al. Predicting maximal exercise ventilation in patients with chronic obstructive pulmonary disease. Chest 1987; 92:253-259

18 Washburn RA, Smith KW, Jette AM, et al. The Physical Activity Scale for the Elderly (PASE): development and evaluation. J Clin Epidemiol 1993; 46:153-162

19 Altman DG, Gore SM, Gardner MJ, et al. Statistical guidelines for contributors to medical journals. Br Med J (Clin Res Ed) 1983 ; 286:1489-1493

20 Kleinbaum D, Kupper L, Muller K. Applied regression analysis and other multivariable methods. 2nd ed. Boston, MA: PWS-KENT Publishing Company, 1988

21 Minotti JR, Christoph I, Oka R, et al. Impaired skeletal muscle function in patients with congestive heart failure: relationship to systemic exercise performance J Clin Invest 1991; 88:2077-2082

22 Harrington D, Anker SD, Chua TP, et al. Skeletal muscle function and its relation to exercise tolerance in chronic heart failure. J Am Coll Cardiol 1997; 30:1758-1764

23 Gosker HR, Wouters EF, van der Vusse GJ, et al. Skeletal muscle dysfunction in chronic obstructive pulmonary disease and chronic heart failure: underlying mechanisms and therapy perspectives. Am J Clin Nutr 2000; 71:1033-1047

24 Puri S, Baker BL, Dutka DP, et al. Reduced alveolar-capillary membrane diffusing capacity in chronic heart failure: its pathophysiological relevance and relationship to exercise performance. Circulation 1995; 91:2769-2774

25 Render ML, Weinstein AS, Blaustein AS. Left ventricular dysfunction in deteriorating patients with chronic obstructive pulmonary disease. Chest 1995; 107:162-168

26 Chabot F, Schrijen F, Poincelot F, et al. Interpretation of high wedge pressure on exercise in patients with chronic obstructive pulmonary disease. Cardiology 2001; 95:139-145 
27 Khan MA, Sinha S, Hayton S, et al. A normal electrocardiogram precludes the need for left ventriculography in the assessment of coronary artery disease. Heart 1998; 79:262267

28 Matthay RA, Berger HJ, Davies RA, et al. Right and left ventricular exercise performance in chronic obstructive pulmonary disease: radionuclide assessment. Ann Intern Med 1980; 93:234-239
29 Medvegy M, Antaloczy Z. Clinical significance of incomplete right bundle branch block. Orv Hetil 1993; 134:1525-8

30 Mauric AT, Samani NJ, de Bono DP. When should we diagnose incomplete right bundle branch block? Eur Heart J 1993; 14:602-606

31 Schena M, Clini E, Errera D, et al. Echo-Doppler evaluation of left ventricular impairment in chronic cor pulmonale. Chest 1996; 109:1446-1451

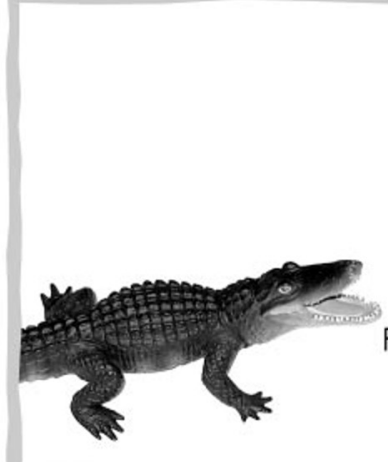

Update your medical knowledge.

Improve your practice management skills.

Maximize the care you provide your patients.

Network with other health professionals.

For details about CHEST 2003 or to register, visit < www.chestnet.org/CHEST/>

or call ACCP Member Services: 800-343-2227 or 847-498-1400.

Register by August 29 for early registration discounts. 